\title{
A WOMAN WITH PURPLE TOES AFTER INTRA- ARTICULAR HYALURONIC ACID ADMINISTRATION
}

\author{
Valentina Broshtilova ${ }^{1}$, Dimitar Nikolov ${ }^{2}$, Filka Georgieva $^{3}$, Sonya Marina ${ }^{3}$ \\ ${ }^{1}$ Department of Dermatology and Venereology, Faculty of Medicine, \\ Medical University-Sofia, Bulgaria \\ ${ }^{2}$ Department of Vascular Surgery, Tokuda Hospital, Sofia, Bulgaria \\ ${ }^{3}$ Department of Infectious Diseases, Parasitology and Dermato-venereology, \\ Medical University of Varna, Bulgaria
}

\begin{abstract}
Intra-articular injected hyaluronic acid provides pain relief and functional improvements in patients with gonarthrosis. We present a 92 -year-old woman with iatrogenic blue toe syndrome after intra-articular injection of hyaluronic acid. This is an anecdotally rare complication, which aims to heighten the clinician's awareness on the possible intervention pitfalls and spectrum of therapeutic indications.
\end{abstract}

Keywords: hyaluronic acid, blue toe syndrome

\section{INTRODUCTION}

Intra-articular injected hyaluronic acid provides pain relief and functional improvements in patients with gonarthrosis (1). The treatment has been highly recognized since 1997 as a first-line interventional therapy, which has a good pain-reducing effect, improving synovial oxygen partial pressure, intra-articular temperature and Lequesne score (2). A few side effects, mostly related to the technique of the intervention, have been described (3).

Herein, a unique case of blue toe syndrome upon intra-articular hyaluronic acid intervention is reported. The special therapeutic indications and possible intervention pitfalls are thoroughly discussed.

\footnotetext{
Address for correspondence:

Valentina Broshtilova

Department of Dermatology and Venereology

Faculty of Medicine

Medical University Sofia

15 Acad. I. E. Geshov Blvd

Sofia, Bulgaria

e-mail:broshtilova@mail.bg
}

Received: June 26, 2017

Accepted: June 30, 2017

\section{CASE REPORT}

A 92-year-old woman presented to the Dermatology Department with severe pain and violent discoloration of the volar aspect of the right lower leg and toes. A week prior to admission she had undergone bilateral intra-articular administration of hyaluronic acid, which was done to improve functional parameters and to reduce the pain from a long-lasting destructive gonarthrosis. During the procedure she complained of sudden discomfort followed by severe pain localized to the back of the right foot. Subsequent grey discoloration of the great toe appeared and spread to the third and fourth toes of the same foot overnight. The ischemic lesions continued to grow, became confluent, and caused unbearable pain. The patient was, otherwise, known to be in perfect health, with no hypercholesterolemia, ischemic heart disease and congestive cardiac failure. She was a non-smoker and regularly took only food supplements to enhance her cognition.

Examination revealed purple discoloration of the right great, third and fourth toes with evidence of digital infarctions (Fig.1). Deep well-demarcated necrosis localized to the tip of the great toe, the distal margin of the nail plate and nail bed was seen. Star- 
like necrotic changes spread on the volar aspect of the calf (Fig.2). Her blood pressure was $120 / 80 \mathrm{mmHg}$ and no murmurs or bruits were audible. Lower limb pulses were all palpable and Doppler pressure studies suggested small vessel occlusion without significant large vessel disease. Investigations revealed: hemoglobin $13.2 \mathrm{~g} / \mathrm{dl}$, platelets $346 \times 109 / 1$, erythrocyte sedimentation rate (ESR) $26 \mathrm{~mm} / \mathrm{h}$, white blood cells 9.5 x 109/1 (neutrophils 4.6, lymphocytes 1.3, monocytes 0.6 , eosinophils 0.1 , basophils 0.1 ). Na $141 \mathrm{mmol} / \mathrm{l}, \mathrm{K}$ $4.7 \mathrm{mmol} / \mathrm{l}$, urea $12.1 \mathrm{mmol} / \mathrm{l}$, creatinine $169 \mathrm{mmol} / \mathrm{l}$, cholesterol $3.6 \mathrm{mmol} / \mathrm{l}$, auto-immune profile and ANCA negative. Electrocardiogram showed no pathological changes. Echocardiography and abdominal ultrasound were within normal ranges.

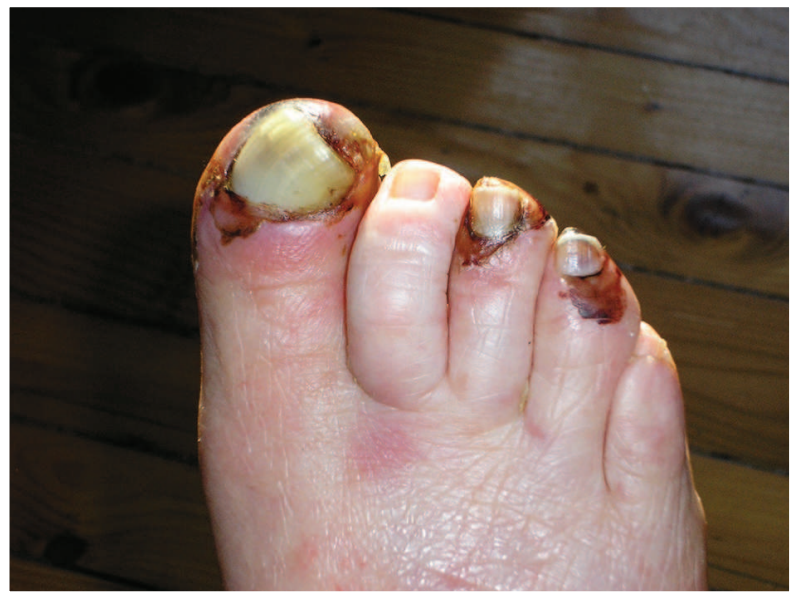

Fig. 1. Purple discoloration of the right great, third and fourth toes with evidence of digital infarctions

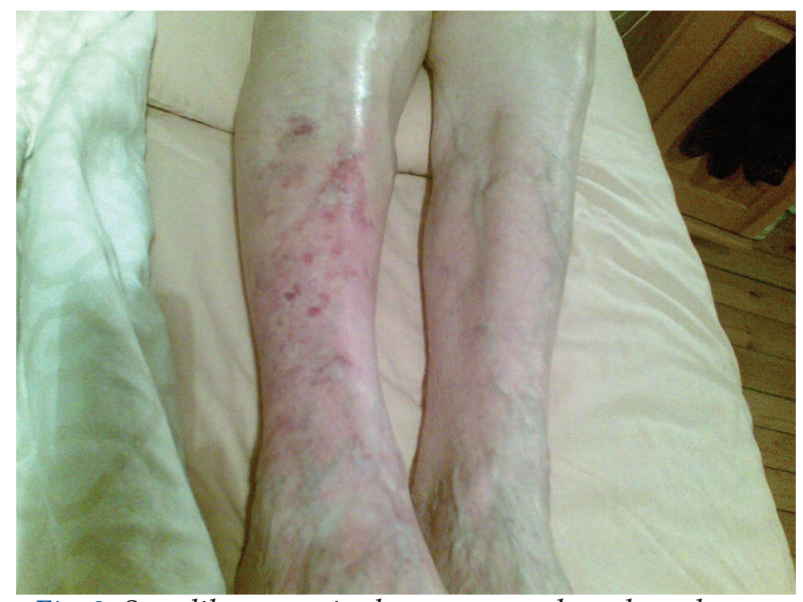

Fig. 2. Star-like necrotic changes spread on the volar aspect of the calf
The presence of pedal pulses with digital infarction suggested small vessel disease. Therefore, the possibility of small arterioles hyaluronic acid embolization upon the intra-articular intervention was hypothesized. Pentoxifylline was introduced for 1 month in combination with topical dressings and appropriate antiseptic care. Demarcated areas of necrosis were removed surgically and secondary epithelialization was achieved in the following 3 months.

\section{DISCUSSION}

Blue toe syndrome is a well-recognized but probably underdiagnosed disorder, in which most commonly cholesterol crystals embolize from atherosclerotic plaques and occlude peripheral arterioles (4). The reported incidence is variable, ranging from 6.2 cases per million population per year to one case every two weeks $(5,6)$. The typical patient is an elderly male with a history of hypertension and atherosclerotic disease (7). The more cardiovascular atherosclerotic factors are present, the more likely the diagnosis is. Although the condition can occur spontaneously, very often it affects subjects with severe generalized atherosclerotic disease.

Iatrogenic interventions, alone or in combined regimens with antithrombolytic and anti-coagulation drugs, are recognized precipitants of blue toe syndrome. Mechanical disruption of thrombus overlying atheroma, e.g., following angiography, angioplasty or vascular surgery is very likely to occur (8). During the intervention the plaque is exposed to the general circulation and goes to the small-diameter arteries (9). The increasing use of these techniques should increase the vigilance for the more frequent development of blue toe syndrome.

The vasculature of the lower leg consists of many collaterals, which join in two profound circles around the knee joint and ankle (10). The main arterial branch on the back of the foot derives from a.tibialis anterior. Presumably, during the intra-articular intervention of the right knee joint, small amounts of hyaluronic acid was injected to one of the two recurrent tibial arteries and introduced to the anterior tibial artery. Apart from malpractice, another possible reason for the developing of the condition in our patient may be an anatomic variation of a branch of the anterior tibial artery, present only in her right lower leg. Such a peculiarity could ex- 
Valentina Broshtilova, Dimitar Nikolov, Filka Georgieva et al.

plain the very unusual presentation of the blue toe syndrome described.

The clinical picture of blue toe syndrome presents with lower extremity pain, livedo reticularis, purpura, cyanosis, "purple toes", and cutaneous necrosis (11). Fever, myalgia, weight loss, gastrointestinal bleeding, vascular bruits, encephalopathy, altered mental state, and pancreatitis could also be seen in the extended disease (12). Laboratory features consist of elevated erythrocyte sedimentation rate, thrombocytopenia, abnormal liver function tests and creatine kinase, elevated serum urea and creatinine, and hypocomplementemia (13). If at all possible, the diagnosis should be confirmed histologically by tissue biopsy of the skin to reveal embolization of the arterioles. In our case the old age of the patient and the lack of compliance avoided histological verification. The differential diagnosis ruled out systemic vasculitis, cholesterol emboli, and drug-induced leukocytoclastic vasculitis. The clinical features of ischemic necrosis with lack of palpable purpura and edema, however, concluded the diagnosis and optimized complex therapeutic measures. Such side effect of intra-articular intervention is anecdotally rare, and has not been reported before.

\section{CONCLUSION}

Clinicians should have a heightened awareness of blue toe syndrome as a possible side effect of intra-articular interventions. In these cases the disease bears the same clinical characteristics as cholesterol crystal embolism, which has to be ruled out. Antiplatelet therapy and rheological medications, together with appropriate topical dressings, should be applied in the complex therapeutic regimen for these patients.

\section{REFERENCES}

1. Bennell KL, Hunter DJ, Hincan RS. Management of osteoarthritis of the knee. BMJ. 2012; 345: 4934. doi: 10.1136/bmj.e4934

2. Schneider U, Miltner O, Graf J, Thomsen M, Niethard FU. Mechanism of action of hyaluronic acid in gonarthrosis of both knee joints in a right/left comparison. Study of dynamometry, oxygen partial pressure, temperature and Lequesne score. $\mathrm{Z}$ Orthop Ihre Grenzgeb. 1997; 135(4): 341-7. doi: 10.1055/s-2008-1039399
3. Kon E, Firaldo G, Drobnic M, Madry H, Jelic M, van Dijk N, Della Villa S. Non-surgical management of early knee osteoarthritis. Knee Surg Sports Traumatol Arthrosc. 2012; 20(3): 436-9. doi: 10.1007/s00167-011-1713-8

4. Saric M, Kronzon I. Aortic atherosclerosis and embolic events. Curr Cardiol Rep. 2012; 14(3): 342-9. doi: 10.1007/s11886-012-0261-2

5. Moolenar W, Lamers CBHW. Cholesterol crystal embolism in the Netherlands. Arch Intern Med. 1996;156(6):653-7.

6. Mayo RR, Swartz RD. Redefining the incidence of clinically detectable atheroembolism. Am J Med. 1996;100(5):524-9.

7. Robson MG, Scoble JE. Atheroembolic disease. Br J Hosp Med. 1996;55(10):648-52.

8. Varis J, Kuusniemi K, Heiro M, Javelainen H. Blue toe syndrome - a rare but possible complication of anti-coagulant therapy. Duodecim. 2011; 127(11): 1154-7.

9. Nakazawa K, Ohta T, Fujimoto M, Imamura $H$, Hashimoto N. Case report of cholesterol embolism 1 month after carotic stenting. No Shinkei Geka. 2007; 35(8): 807-15.

10. Heuschmid M, Ketelsen D, Brechtel K. Advanced interventional techniques in the treatment of peripheral artery disease below the knee. Rofo. 2012; 184(7): 607-17. doi: 10.1055/s-0031-1299332

11. Falanga F, Fine MJ, Kapoor WN. The cutaneous manifestations of cholesterol crystal embolism. Arch Dermatol. 1986; 122(10):1194-8.

12. Spittell PC, Seward JB, Hallett J. Mobile thrombi in the abdominal aorta in cases of lower extremity embolic arterial occlusion: value of extended transthoracic echocardiography. Am Heart J. 2000; 139(2 Pt 1): 241-4.

13. Begon E, Bouilly P, Cheysson E, Cohen P, Bachmeyer $\mathrm{C}$. Isolated blue toe syndrome as presenting sign of Wegener granulomatosis. Am J Med. 2010; 123(7): 7-8. doi: 10.1016/j.amjmed.2009.11.024 